\title{
Tensiones y descontentos en torno al traspaso de la Policía Federal Argentina*
}

DOI: https://doi.org/10.18046/recs.i31.3731

\author{
Tensions and Discontents Regarding the Transfer \\ of the Policia Federal Argentina
}

\author{
Mariana Da Silva-Lorenz ${ }^{* *}$ \\ Universidad de Buenos Aires (Buenos Aires, Argentina) \\ Mariana Galvani ${ }^{* * *}$ \\ Universidad de Buenos Aires (Buenos Aires, Argentina)
}

\begin{abstract}
* Este artículo forma parte de una investigación más amplia realizada por ambas autoras en el marco de los proyectos: PICT "El Estado y la seguridad pública: obediencia, desobediencia y autoridad en las fuerzas policiales y de seguridad de la Argentina contemporánea", y UBACYT “Gobierno de la (in)seguridad en el AMBA 2010-2017: fuerzas de seguridad y tecnologías de vigilancia y control”. Asimismo, una versión preliminar del mismo fue presentada en forma oral en la 8. a Conferencia Latinoamericana y Caribeña de Ciencias Sociales, donde las autoras recogieron los comentarios y sugerencias allí realizados para mejorarlo y arribar a la versión que aquí se presenta. Por último, las autoras vienen realizando trabajos sobre la Policía Federal Argentina hace años, tomando como insumos estas investigaciones anteriores (Galvani, 2016; Lorenz, 2017a; 2017b), pero en este trabajo presentan una temática que no habían abordado con anterioridad: las tensiones y descontentos en torno a una modificación en la política securitaria y fuerzas policiales en Argentina. Artículo de investigación recibido el 30.09.2019 y aceptado el 13.04.2020.

** Doctora en Ciencias Sociales por la Universidad de Buenos Aires (Argentina). Instituto de Investigaciones Gino Germani (IIGG). Correo electrónico: marulorenz@gmail.com ORCID: https://orcid.org/oooo-0oo2-7208-9337

*** Doctora en Ciencias Sociales por la Universidad de Buenos Aires (Argentina). Instituto de Investigaciones Gino Germani (IIGG). Correo electrónico: marianacgalvani@gmail.com ORCID: http://orcid.org/oooo-ooo1-5046-5306
\end{abstract}




\section{Cómo citar/How to cite}

Da Silva-Lorenz, Mariana; Galvani, Mariana (2020). Tensiones y descontentos en torno al traspaso de la Policía Federal Argentina. Revista CS, 31, 269-295. https://oi.org/10.18046/ recs.i31.3731 


\section{Resumen}

En 2016, en Argentina se crea la Policía de la Ciudad (PC), para cumplir las funciones de policía en la Ciudad Autónoma de Buenos Aires, rol que desde 1943 y hasta ese momento era llevado a cabo por la Policía Federal Argentina (PFA), excepto en algunas jurisdicciones que eran patrulladas por la Policía Metropolitana, creada en 2008. Esta instauración implicó el traspaso de funcionarios y bienes inmuebles de una policía a la otra. El presente trabajo aborda la transferencia de parte de la PFA a la PC, centrándose en las formas como expresaron su descontento algunos de los expolicías federales incorporados a la nueva policía. Mostramos diferentes formas de manifestarse de estos funcionarios, como agruparse en la calle, quitar colaboración o circular mensajes por redes sociales para oponerse. Estas protestas marcan un punto de inflexión en la tradición de la Policía Federal Argentina.

\section{PALABRAS CLAVE:}

Policía de la Ciudad, Policía Federal Argentina, protesta, traspaso

The Policía de la Ciudad (PC) was created during 2016 in Argentina in order to enforce order in the Autonomous City of Buenos Aires. Since 1943, and unto that moment, that role was played by the Policía Federal Argentina (PFA), except for some jurisdictions that were patrolled by the Policía Metropolitana created in 2008. This implied the transfer of agents and real estate from one law enforcement agency to the other. This paper deals with the transfer of part of the PFA to the PC. The focus is on the ways some ex-members of the PFA transferred to this new police agency demonstrated their displeasure with the situation. Here are described different ways these agents used to voice their discontent which went from gathering in the street, stop working or sending messages through social media to oppose. These protests are a turning point in the tradition of the PFA.

\section{KEYWORDS:}

Policía de la Ciudad, Policía Federal Argentina, protest, transfer 



\section{Introducción}

En el presente trabajo nos proponemos abordar una arista de lo que implicó la transferencia de parte de la Policía Federal Argentina (PFA) a la Policía de la Ciudad de Buenos Aires (PC): las formas de expresión del descontento de algunos de los expolicías federales incorporados a la nueva policía.

En 2016 se creó la PC para cumplir las funciones de policía en la Ciudad Autónoma de Buenos Aires, rol que desde 1943 y hasta ese momento era llevado a cabo por la Policía Federal Argentina, excepto en algunas jurisdicciones que eran patrulladas por la Policía Metropolitana (PM) creada en 2008. Esta instauración implicó el traspaso de funcionarios y bienes inmuebles de una policía a la otra.

Aunque la creación de la Policía de la Ciudad de Buenos Aires se inició, efectivamente, en ese año, se trataba de un proceso con un trasfondo histórico de más larga data y cuyo hito más importante fue la autonomización de la Ciudad de Buenos Aires. En este sentido, Ríos (2016: 142) afirma que "con la automatización de la Ciudad se va a dar un proceso de institucionalización en el que se plantea la preocupación por definir la pertinencia de una policía como herramienta para el gobierno local".

La PC está compuesta por una parte de los miembros de la PFA, la totalidad de los que conformaban la $\mathrm{PM}^{1}$ y el personal que se formó en el Instituto Superior de Seguridad Pública (ISSP) para incorporarse a esta nueva fuerza ${ }^{2}$. Respecto de la PFA, el convenio de traspaso implicó la transferencia de unos 21 ooo efectivos que pertenecían a la Superintendencia de Seguridad Ciudadana, y representaban cerca de la mitad de los miembros de dicha fuerza, sin mediar otro criterio que su pertenencia a esta institución para el cambio. Una particularidad de este proceso es que también se trasladaron los recursos institucionales que la Nación venía utilizando para el cumplimiento de las facultades y funciones transferidas ${ }^{3}$ (Ríos, 2016).

El proceso de transferencia implicó una reconfiguración de la misma PFA y la disolución de la PM, además de la creación de una tercera policía. Vale destacar

1. Esta fuerza contaba con tres comisarías comunales: una en la Comuna 4 (Nueva Pompeya, Parque Patricios, Barracas y La Boca), otra en la Comuna 12 (Villa Urquiza, Villa Pueyrredón, Coghlan y Saavedra), y la tercera en la Comuna 15 (Agronomía, Chacarita, Villa Crespo, Paternal y Villa Ortúzar); y estaba compuesta por 4500 efectivos policiales.

2. Del ISSP egresaron 800 nuevos agentes en 2017; 1980, en 2018; y en febrero de 2019 fueron 1850 los cadetes que iniciaron su formación, por lo que a finales de ese año contaba con 4630 funcionarios exclusivamente formados para la nueva fuerza de la ciudad.

3. Se transfiere entonces no solo el personal y los bienes, sino los recursos materiales para sostener este traspaso. Algo similar a lo sucedido con la creación de las Unidades de Policía de Prevención Local en la Provincia de Buenos Aires. En el Artículo 1. ${ }^{\circ}$ de la Resolución 835, se indica: "Las unidades creadas por la presente serán equipadas, conformadas y financiadas por el presupuesto de la provincia de Buenos Aires”. 
que esta reconfiguración produjo distintas actitudes entre los funcionarios (tanto en los que fueron traspasados como los que continuaron en la PFA), que iban desde la aceptación sin discusión hasta la resistencia abierta a transformarse (con todo lo que este verbo implica), fuera porque se modificó la fuerza a la que pertenecían o porque permanecían en su fuerza de origen, pero bajo otras condiciones. Tanto los traspasados (cómo se los conoció) o transferidos (la forma legal de hacer referencia a este cambio) como los que se quedaron en la fuerza en la que revistaban originalmente vieron sus condiciones de trabajo modificarse. Para quienes dejaron de pertenecer a la PFA para incorporarse a la PC, el traspaso implicó la ruptura del vínculo con una historia, símbolos, valores y rituales construidos por la institución a lo largo de su historia, y con los que sus miembros se identificaban.

La disconformidad de los miembros traspasados de la PFA quedó de manifiesto en varias oportunidades y a través de distintos medios: increpaciones a los funcionarios de gobierno en diferentes actos públicos; circulación de videos y mensajes por redes sociales, y manifestaciones frente a algunos edificios para visibilizar el reclamo (el departamento central de la PFA, la legislatura porteña, la sede del gobierno de la CABA y los ministerios de seguridad de la CABA y la Nación).

Buscaremos en las siguientes líneas abordar algunas de esas tensiones y descontentos que surgieron en torno al traspaso de la Policía Federal Argentina. Se trató de un hecho que, si bien no tomó dimensiones cuantitativas significativas -en ninguna de las manifestaciones observamos más de 40 funcionarios-, sí tuvo una magnitud simbólica considerable, ya que era la primera vez que los miembros de esta fuerza se unían para reclamar colectivamente. No es menor el hecho de que los funcionarios policiales en Argentina estén impedidos legalmente para realizar cualquier tipo de reivindicación grupal.

Para dar cuenta de las expresiones de descontento de los policías federales traspasados, empleamos diversas técnicas cualitativas de recolección y análisis de los datos (Valles, 200o; Vasilachis de Gialdino, 1992). El trabajo de campo tuvo lugar entre octubre de 2016 y agosto de 2019. Realizamos observaciones participantes en tres movilizaciones y protestas en reclamo por el traspaso: la primera el $5 \mathrm{de}$ octubre de 2016, en el departamento central de la PFA, en el marco de la presentación de la Policía de la Ciudad por parte del jefe de gobierno Horacio Rodríguez Larreta en el ISSP; la segunda frente a la sede de gobierno de la CABA, el 11 de abril de 2018; y la última el 27 de junio de ese mismo año en las inmediaciones del Ministerio de Justicia y Seguridad de la Ciudad de Buenos Aires. También se utilizaron técnicas de conversación/narración: 3 entrevistas en profundidad a referentes que encabezaron la protesta, 20 a miembros de la PFA traspasados a la PC en el marco de las observaciones, una entrevista a un funcionario de alta jerarquía en la PC, y conver- 
saciones informales con 10 policías que ya habíamos entrevistado para nuestras investigaciones (Galvani, 2016; Lorenz, 2017a; 2017b). Respecto a las técnicas de documentación, el trabajo lo realizamos incorporando al corpus las siguientes fuentes secundarias: normativa (leyes, decretos y órdenes del día), material que circuló por redes sociales e internet, y artículos periodísticos. La revisión de este material se realizó a lo largo del todo el período de trabajo de campo, prestando especial atención en los momentos más álgidos del conflicto, cuando se producían manifestaciones.

\section{Lo que se pierde en el traspaso: símbolos y derechos laborales}

En 2007, Mauricio Macri asumió como jefe de gobierno porteño e impulsó una reforma a la Ley 24588 -conocida como Ley Cafiero, debido al apellido del senador que realizó el proyecto-, sancionada con amplio apoyo, con el objetivo de permitir que la CABA tuviera su propia fuerza policial para actuar frente a "todas las materias no federales"4. Un año más tarde, específicamente el 28 de octubre de 20o8, la Ley 28942 de Seguridad Pública, sancionada por la Legislatura de la Ciudad de Buenos Aires, creó la Policía Metropolitana. Allí, luego de muchos años de conflictos, quedaron formalizadas varias de las cuestiones que se venían discutiendo desde la autonomización de la Ciudad y la gestión de su propia seguridad. Apenas el 18 de enero de 2016 se aprobó el Convenio 1. $\%$ 16, de transferencia progresiva entre el Estado nacional y la Ciudad Autónoma de Buenos Aires (CABA), donde la última asumió "todas las funciones y facultades de seguridad en todas las materias no federales para ser ejercidas en el ámbito de la Ciudad Autónoma de Buenos Aires". Este proceso finalizó el 17 de noviembre de ese mismo año, cuando la Legislatura de la Ciudad Autónoma de Buenos Aires sancionó la Ley 5688, que daba origen al Sistema Integral de Seguridad Pública y, con él, a la Policía de la Ciudad. Esta nueva policía dependía del Ministerio de Justicia y Seguridad de la Ciudad.

La creación de la PC comportó varias cuestiones novedosas. Por un lado, era una fuerza de seguridad propia del gobierno de la ciudad de Buenos Aires, culminando

4. El traspaso y la creación de una nueva fuerza de seguridad se sustentaban en la autonomía legislativa, jurisdiccional y administrativa de la CABA, sancionada en la reforma constitucional de 1994, y concretada dos años después, cuando la Ciudad dictó su propia Constitución. En ella, se consagró formalmente su autonomía, la cual incluía gestionar su propio servicio de seguridad pública. Sin embargo, la Ley 24588 establecía que la Policía Federal Argentina, dependiente del Poder Ejecutivo Nacional, continuaría siendo la encargada de proteger a las personas y bienes en la Ciudad, y que si esta localidad deseaba crear un organismo de seguridad propio debía solicitar autorización al Congreso Nacional. 
un proceso de autonomización y gestión de la propia seguridad iniciado en 1994 (Anitua, 2004; Ríos, 2010; 2016); y, por otro, no tenía, al momento de su creación, funcionarios propios. Esto último implicó la redefinición y absorción de personal de otras dos fuerzas policiales preexistentes: la PFA y la PM. Esta nueva fuerza, producto de dos que ya existían, con sus respectivas tradiciones, símbolos, formas de organización e idiosincrasias no estuvo-ni está- exenta de tensiones y descontentos.

La PFA tiene una historia, símbolos, valores y rituales que la identifican y distinguen de otras profesiones y de otras fuerzas policiales y de seguridad. Algunos de los motivos de esta diferenciación pueden deberse a que, tal como indica Galvani (2016), ofrece mejores salarios y tiene un criterio de selección más riguroso que las demás. Por otro lado, no podemos dejar de tomar en consideración que una de las características de la PFA es, precisamente, que es federal, por lo que sus funcionarios están habilitados a actuar a lo largo y a lo ancho de todo el territorio nacional, capacidad que quedaba limitada al área de la CABA al ser traspasados. Además, aunque la PFA fue creada formalmente en 1943, sus historiadores ubican sus inicios hace unos 400 años, en la etapa colonial temprana (Rodríguez, 1978; Rodríguez; Zappietro, 1999; Zappietro, 2005; 2010). Esa manera de construir la historia ligada a los orígenes de la Argentina tiene implicancias en la forma como la institución se construye a sí misma y a los sujetos que la componen. Esta historización implica una construcción en espejo de una institución que busca reflejarse en una imagen de nación.

En la primera protesta a la que asistimos en nuestro trabajo de campo (del 5 de octubre de 2016, ya mencionada), un funcionario herido en acto de servicio, ya retirado y con el que conversamos, vestía una remera cargada de simbolismos: al frente tenía estampada la foto de alguien a quien describió como su ídolo, el comisario Villars; en una manga tenía la inscripción "Macri traidor", y en la otra, "Larreta traidor"; por último, en la parte trasera se leía la frase "No quiero ser policía municipal". Resulta más que significativo también lo que el mismo funcionario declarara en un reportaje que le realizó Télam, en el marco de otra protesta en contra del traspaso, durante enero de 2017: "Es una policía con 200 años de historia. Tenía las brigadas bien conformadas, los edictos. Los políticos nos fueron sacando cosas y hoy Macri y Larreta nos sacaron 200 años de historia" "Policías y familiares...”, 2017). No es casual que el funcionario remita a los edictos policiales ${ }^{6}$,

5. Uno de los creadores del grupo parapolicial terrorista de extrema derecha conocido como Triple A (o Alianza Anticomunista Argentina), que funcionó en el país en la década de 1970.

6. Existe un universo de faltas y pequeños delitos que no están contemplados en el Código Penal. Este vacío fue llenado desde principios de siglo por los edictos policiales, nacidos de las Leyes de vagos y maleantes de la Corona española del siglo XIX. Los edictos fueron reemplazados por el Código Contravencional de la CABA, en 1998. 
ya que esta fue la primera intervención política que sufrió la PFA desde el comienzo de la democracia. Si bien no se trató de la modificación de la legislación que rige su accionar directamente, la eliminación de esta normativa, en su momento, fue una fuerte restricción a las facultades de los policías federales que ejercían funciones de policía en la CABA (Galvani, 2009).

Entre los dichos y las inscripciones en la camiseta de este exmiembro de la PFA, sobresalen dos cuestiones importantes que mencionábamos con anterioridad: la primera es que los funcionarios de esta institución consideran que la misma tiene una trayectoria con la que esta nueva fuerza de seguridad a la que fueron traspasados no cuenta; $y$, en segundo lugar, que su ámbito de intervención se ve reducido con esta reforma. Sobre este último aspecto, otro funcionario reflexionaba: "Somos como los pitufos7, pero de la CABA" (funcionario, comunicación personal, 11.04.2018).

En general, los miembros de las fuerzas de seguridad se refieren a la institución a la que pertenecen como una gran familia. Calandrón (2014:143) explica claramente el significado de esta asociación:

Las largas convivencias, la presencia constante y la sensación de lidiar con problemas parecidos generaban, por un lado, comprensión y apoyo mutuo; y por el otro enojos y competitividad. La tensión entre el afecto y el enfrentamiento generados en las experiencias cotidianas compartidas aumentaban la fertilidad de la metáfora policial (familia).

Se genera entonces un lazo identitario entre los funcionarios que se identifican con ciertos símbolos, ritos y una historia en común. Las fuerzas de seguridad interpelan a los sujetos que la componen en una clave identitaria ligada a estos elementos que los aúnan más que en términos de trabajadores, lo cual es significativo en los policías que construyen un sentimiento de pertenencia muy fuerte. Estas apelaciones tienen un fuerte peso al momento de la incorporación a la PC, ya que el traspaso de una policía a otra tiene una carga emotiva que implica romper con los lazos que los convertían en parte de la familia de la PFA.

La importancia de los símbolos asociados a la institución y la relevancia que cobran para sus integrantes también quedaron de manifiesto en la entrevista que realizamos a un funcionario que se incorporó a la PFA en 2003 y fue traspasado en 2016. Durante la conversación, nos relató cómo se realizaba burocráticamente el trámite de la transferencia de una fuerza a otra: todos los transferidos debían concurrir al Departamento Central de la Policía Federal Argentina y entregar la

7. Forma despectiva con la que se hace referencia a los funcionarios de las Unidades de Policía de Prevención Local (fuerzas de seguridad municipales) por las similitudes del uniforme que visten con el dibujo animado. 
chapa y credencial. Cuando le tocó su turno, al llegar al lugar, no pudo contener las lágrimas. Frente a la pregunta de su hija, quien lo acompañó a hacer el trámite, de por qué lloraba, le respondió que con la chapa "se va un poco toda mi vida" (funcionario, comunicación personal, 14.05.2019). Mientras nos narraba la anécdota volvió a emocionarse y, mientras se secaba las lágrimas, agregó que había sido muy duro para él desprenderse de su historia en la PFA.

Respecto a un elemento fundamental de la investidura policial, el uniforme, nos dijo que a quienes provienen de la PFA y fueron traspasados les cuesta identificarse con los colores del nuevo atuendo. Para algunos entrevistados se asemeja a la vestimenta que llevan los trabajadores de las estaciones de servicio Axion o el correo postal Oca, empresas privadas que nada tienen que ver con la función policial. Incluso nos cuenta que se han escrito poemas que evocan el color azul del uniforme de la PFA. De hecho, existen varios volúmenes de la Editorial Policial bajo el titulo Letras en azul que compilan poesías y cuentos escritos por funcionarios o familiares en los que se hace referencia a este tema. Citamos algunos ejemplos:

\section{Hombres de azul}

Su uniforme es azul

como el color del mar

por sus venas corre sangre

siempre lista a ofrendar

SARGENTO 1. ${ }^{\circ}$ (R) JORGE NORBERTO FULCO (PFA, 2006:35)

\section{El ángel azul}

Tú eres un ángel custodio

de los que se visten de azul

del azul de la nobleza

del cielo que tú miras

CECILIA DOBAL ANDINO (PFA, 2000: 39)

El uniforme es también un símbolo que, como la chapa y la credencial, tenía que ser entregado para incorporarse a la nueva fuerza. Ese despojo de algo que los conformaba como parte de la PFA es relatado como doloroso, incluso por aquellos policías que no manifestaron su disconformidad e interpretaron la transferencia como una responsabilidad más dentro de sus tareas policiales. De hecho, como se desliza en los poemas que citábamos, los policías federales consideran que tienen sangre azul, por una identificación con el uniforme.

Pero centrémonos ahora en cuáles son los principales reclamos de estos funcionarios que se manifiestan en contra el traspaso, en cuanto a las condiciones y derechos laborales que se pierden. Un primer punto que genera malestar es que temen perder 
su caja de retiro ${ }^{8}$, que es un beneficio muy preciado en la fuerza. A ella aportan los efectivos activos y retirados, y pueden acceder a la jubilación con 10 años de servicio ininterrumpido, si cumplen con la edad. En ese sentido, una problemática que se genera es si la PC reconocerá la antigüedad acumulada por los funcionarios en sus fuerzas de origen ${ }^{9}$.

También hay conflicto en torno a la obra social: los funcionarios de la PM contaban con una cobertura de salud privada (OSDE), mientras que la PFA cuenta con una mutual policial, que depende de la Obra Social autónoma de la fuerza. Los efectivos se atienden en el Complejo Médico Churruca Visca y suponen que pasarse a una prepaga no les da estabilidad. Si bien en muchas oportunidades, según comentan miembros de la PFA, el servicio prestado por la obra social policial era muy criticado por la ineficiencia de su atención, ahora aparece como un valor relevante. Incluso el hospital Churruca cobra un sentido simbólico profundo: "no me importa esperar a ser atendido porque es mi casa" o "nací en ese hospital" (funcionario, comunicación personal, 17.05.2019). A su vez, el paso de una obra social propia a una prepaga no garantiza la continuidad y calidad de la prestación; si bien la que tienen actualmente es una de las prepagas más prestigiosas, si el gobierno de la ciudad rescinde el contrato pueden empeorar las condiciones y prestaciones.

Por otro lado, existen algunas demandas sobre dónde quedarán destinados a prestar servicios. Algunos policías provenientes del interior del país se unieron a la PFA con la esperanza de poder trabajar en sus provincias de origen, cerca de sus familias. Posibilidad que queda descartada al ser traspasados y tener que prestar servicio en el ámbito de la CABA.

El régimen de trabajo también constituye un problema. Los funcionarios de la PFA trabajan bajo un sistema de rotación por $\operatorname{cuartos}^{10} \mathrm{y}$ las tareas que cumplen por

8. De hecho, los funcionarios denuncian que desde enero de 2017 no se les están realizando los aportes previsionales correspondientes en la Administración Nacional de la Seguridad Social.

9. En la Ley 5688, Artículo 221, se dice que: "Se computan los servicios prestados con anterioridad al ingreso a la Policía de la Ciudad en las Fuerzas Armadas de la Nación, Fuerzas de Seguridad, Policías Provinciales y Servicio Penitenciario Federal y Provinciales con estado militar (salvo servicio militar obligatorio), estado policial o estado penitenciario, y en el Cuerpo de Bomberos de la Ciudad, a partir de los veinte (20) años de servicio".

10. Es decir, cumplirá un servicio de 6 horas en el mismo turno (o a 6, 6 a 12, 12 a 18, 18 a o) durante toda una semana con un franco semanal. La rotación de los turnos es en sentido antihorario. El último viernes del mes los funcionarios que se encuentran de servicio en el turno de 12 a 18 tendrán cuatro días de franco, reincorporándose el día miércoles siguiente en el cuarto de 6 a 12. 
fuera de este servicio ordinario realizando los denominados servicios adicionales ${ }^{11}$ representan una parte importante de sus ingresos. En la PC el régimen es de 8 horas de trabajo y los policías traspasados consideran que el sueldo no logra igualar los ingresos que percibían en la PFA sumando el servicio ordinario y adicional. Otro elemento que cambió es que, en la Policía Federal, cuando se sanciona a un agente, este queda bajo arresto, es decir, recargado de trabajo; mientras que en la PC esto es diferente, pues a los días de arresto se les suma un descuento salarial importante, es decir, que se sanciona dos veces el mismo hecho.

Por último, también hay gran malestar en cuanto al ordenamiento jerárquico de esta nueva fuerza de seguridad, que debe contemplar el ordenamiento por escalafón de los funcionarios provenientes de la PM y la PFA. Algunos de los traspasados a la $\mathrm{PC}$ provenientes de esta última fuerza, principalmente los que revistaban como suboficiales u oficiales subalternos, consideran que en el nuevo escalafón quedan equiparados con funcionarios provenientes de la PM con menos antigüedad y experiencia, e incluso con aquellos que recién egresan del ISSP para incorporarse a las filas de la nueva institución.

La transferencia o traspaso implicaba, para los policías, dejar de lado la manera en que habían construido su relación con la institución. Todos se vieron afectados en ese sentido, y no les resultó un trámite fácil, algo de ritual de cierre estaba involucrado en la entrega de esos elementos que los identificaban con la PFA. A su vez, esto se superpuso con pérdidas laborales concretas. En los discursos de nuestros entrevistados se solapan ambos argumentos.

\section{Mas disconformes unos que otros. ¿Vamos a volver?}

La disconformidad de algunos de los miembros de la PFA traspasados quedó de manifiesto en varias oportunidades. A fines de septiembre de 2016, durante un acto de entrega de diplomas para policías federales que terminaron un curso de actualización profesional en el Instituto Superior de la Policía Metropolitana, cuando habló Guillermo Calviño, jefe de la Policía Federal de la Ciudad de Buenos Aires, una agente reclamó: "Yo quiero volver a mi provincia y quiero ser escuchada" (Conclusión TV, 2016), y fue aplaudida por sus compañeros. El 5 de octubre de ese mismo año, el mismo día que el jefe de gobierno porteño Horacio Rodríguez Larreta presentaba a la PC en el ISSP, hubo una manifestación frente al Departamento Central de la

11. Actividades que los funcionarios policiales cumplen fuera del destino principal que se les ha asignado en alguna otra entidad civil o comercial, pública o privada, prestando función especial de seguridad de personas y bienes. 
PFA, donde policías retirados y familiares del personal policial se congregaron para rechazar el traspaso. Luego, en abril de 2017, el ministro porteño de Seguridad mantenía un encuentro con un grupo de policías de la Ciudad, pero tuvo que retirarse ante un duro reclamo de los funcionarios por falta de recursos y respuestas (Rebelión en la Policía..., 2017). Durante los primeros meses de 2018, por las redes sociales circuló un video de 9 minutos de duración, denominado Quiero volver a la $P F A$. Allí, un exagente de la PFA solicitaba su reincorporación a la fuerza y la de todos los traspasados. El archivo consistía en la recopilación de videos caseros de hombres y mujeres, algunos con sus hijos, otros solos, algunos con uniforme y otros vestidos de civil, reclamando este regreso ${ }^{12}$. El 26 de marzo, un grupo de policías se trasladó desde Plaza de Mayo hasta la Legislatura porteña para rechazar su traspaso a la Policía de la Ciudad ("Policías en acción...", 2018). Ante la falta de respuestas, el 10 de abril se movilizaron frente a la sede del gobierno de la CABA, el 24 de mayo la protesta fue frente a la sede del Ministerio de Seguridad de la Nación de la calle Gelly y Obes, y durante los meses siguientes en varias oportunidades se congregaron en el Ministerio de Seguridad de la Ciudad.

No todos los funcionarios traspasados se manifiestan en contra de esta medida y entre los que no están de acuerdo encontramos distintos tipos de disconformidad: algunos plantean que deberían tenerse en cuenta todos estos reclamos a los que hacíamos alusión en el apartado anterior, pero que podrían adaptarse a la nueva fuerza, otros directamente quieren volver a la PFA sin importar cuánto se vean modificadas sus condiciones laborales.

\section{Los policías como manifestantes}

A partir de las distintas investigaciones que hemos llevado a cabo sobre las fuerzas de seguridad (Galvani, 2016; Lorenz, 2017a; 2017b), y coincidiendo con lo que otros autores (Bover; Maglia, 2017; Calandrón, 2014; Frederic, 2009; Garriga-Zucal, 2014; 2016; Monjardet, 2010; Sirimarco, 2009; Suarez de Garay, 2006) han expresado, encontramos ciertas características que alejan a los policías de las formas tradicionales de reivindicación laboral. Una es el carácter permanente de la actividad como derivación de una reglamentación que trasciende la vida pública de los(as) agentes para pautar también sus vidas privadas. Los funcionarios policiales entienden su quehacer profesional como particularmente riesgoso, continuo y vocacional y, en esta dirección, lo consideran más como un servicio, una misión, que como un trabajo, lo 
que los aleja de pensarse como trabajadores y, por ende, recurrir a métodos de agrupamiento o expresión propios de otros sectores (como la manifestación o la huelga).

Hay algunos elementos que contribuyen a consolidar esta representación que los policías construyen sobre su profesión. En primer lugar, durante su paso por los institutos de formación, los aspirantes a integrar las fuerzas de seguridad reciben una beca de estudios, un salario mientras se están capacitando, lo que anula la brecha entre formación y trabajo que tienen la mayoría de las profesiones y oficios, distanciándolos de reconocerse como trabajadores.

En segundo lugar, si bien no es posible encontrar una definición unívoca, cerrada e inmutable de aquello que se representa y define como trabajo policial, un elemento que, en general, los funcionarios consideran central de su labor es su carácter permanente. En principio, perciben su tarea como particularmente riesgosa, ya que disponen de una herramienta de trabajo que está diseñada para matar-un arma-, y se relacionan con personas que entienden están dispuestas a atentar contra su integridad física, los delincuentes. Por este grado de exposición constante al peligro, los policías consideran que deben estar siempre atentos y no deponer jamás la actitud de sospecha (Lorenz, 2017a; 2017b).

Además, existen dos elementos del marco legal que rige a los policías -en particular a los miembros de la PFA- que contribuyen a que entiendan el suyo como un trabajo al que deben dedicarse permanentemente. Por una parte, ya que, según el Decreto-Ley 333/58 (Art. 4.1) y el Decreto 6580/58 (Art. 133), los policías son los encargados de resguardar el orden público, las buenas costumbres y la moralidad, desde su punto de vista deben ser ejemplo de una conducta moralmente intachable dentro y fuera de su horario de servicio, dado que no se puede ser guardián de las costumbres ajenas si no se empieza por las propias. La otra reglamentación es el estado policial-dispuesto en la Ley 21965 y el Decreto 1866/1983-, que determina que los funcionarios deben cumplir todas las disposiciones de la institución las 24 horas del día, los 365 días del año, hasta que se produzca su fallecimiento o baja. Este estado no solo permite que los policías consideren la suya como una tarea permanente, sino que también marca algunas diferencias con el resto del conjunto social. Los miembros de las fuerzas de seguridad deben observar siempre las disposiciones legales impuestas por las instituciones a las que pertenecen, a diferencia de cualquier otro trabajador que tiene ciertos derechos, obligaciones y prohibiciones que solo rigen mientras está en ejercicio de sus funciones.

En este sentido, los funcionarios policiales consideran que tienen un grado inigualable de entrega a su trabajo. Esto se debe, afirman, a que le dedican la mayor parte de su tiempo al ámbito laboral, descuidando el personal. Lo que les trae aparejados muchos inconvenientes en esta área de su vida, que se evidenciarían, por 
ejemplo, en el índice de divorcios que entienden es alto. Las motivaciones que dan los funcionarios para destinarle tanto tiempo a su vida laboral descuidando la esfera privada, aun a pesar de los perjuicios que esto les genera, son dos: en primer lugar, consideran que el salario que reciben por su servicio ordinario no es suficiente para cubrir sus necesidades básicas y entonces realizan servicios adicionales y prevencionales $^{13}$. Por otra parte, desde su perspectiva, tienen voluntad de dedicarse a su tarea $y$, por esa razón, no ven como un inconveniente que sea de tiempo completo. En general, los funcionarios consideran que, a diferencia del resto del conjunto social, que se remite a cumplir la jornada laboral, ellos tienen un mayor grado de entrega para con su trabajo. En una situación de emergencia, suspenderán su franco para acudir al deber, no solo porque así lo dictamina el estado policial, sino porque han elegido dedicarse a brindar este servicio.

Otro elemento que, según los policías, caracteriza su labor y les impide entenderse como trabajadores, es su carácter vocacional. Más allá de la multiplicidad de motivos que puedan esgrimirse para el ingreso a una fuerza de seguridad, entendemos que lo que los agentes denominan vocación, son justificaciones y explicaciones que pretenden darle sentido al sacrificio y los riesgos que, según ellos, implica su profesión. Sacrificio y riegos que estiman no son reconocidos en términos materiales, porque la remuneración recibida es escasa, ni espirituales, ya que no reciben el respeto que consideran merece su tarea por parte de la población (Bover; Maglia, 2017; Frederic, 2009; Galvani, 2016; Garriga-Zucal, 2014; 2016; Lorenz, 2017a; 2017b; Melotto, 2013).

Los policías entienden que entregan su tiempo e integridad física para proteger la propiedad y la vida del resto de los civiles tal como está regulado en su normativa, sobreponiéndose a las múltiples dificultades que dicen encontrar en el desempeño profesional cotidiano (falta de equipamiento, de personal, de facultades legales, bajos salarios, etc.). La institución, al lograr imponer, a través de sus publicaciones y discursos, la visión del quehacer policial como una causa superior a los intereses particulares, borra la idea de trabajo entre sus miembros (Galvani, 2016). También mediante esta vía conseguirá que todos los policías, incluso aquellos que ingresaron por una cuestión económica, consideren que cumplen su labor motivados por la pasión por lo que hacen: amor por su trabajo que consideran superior al que tiene el resto de la sociedad.

Un último elemento que, sin dudas, contribuye a que a los miembros de las fuerzas de seguridad -y en particular los miembros de la PFA- se les dificulte entenderse

13. El que continúa luego de cumplir el ordinario para aquellos funcionarios que hacen tareas administrativas dentro de una comisaría y quienes están destinados a distintos objetivos en la vía pública (ya sea un puesto fijo, móvil o a estén cargo de la seguridad de una entidad bancaria o restaurante). 
como trabajadores es que se les impide "integrar, participar o adherir al accionar de entidades políticas, culturales o religiosas que atenten contra la tradición, la Institución, la Patria y sus símbolos"; a la vez que se les prohíbe participar en "actividades políticas, partidarias o gremiales, ni el desempeño de funciones públicas propias de cargos electivos", según los Artículos 8 y 9 de la Ley 21 965, respectivamente. Además, los policías no pueden formar parte de una organización sindical, dado que no pueden reivindicar derechos colectivos ${ }^{14}$. Nos parece importante remarcarlo, dado que se les exige a los funcionarios -puesto que es parte central de sus tareasque sean los primeros en defender los derechos de todos los ciudadanos, mientras que los suyos les son cercenados. Eso les permite, ya que no pueden verlos como a iguales, reprimir a otros trabajadores que se manifiestan por sus derechos laborales, como también les impide pensar en reclamar por los propios.

Más allá de estas limitaciones normativas, en nuestro país la libertad sindical policial es obstaculizada por el poder político aduciendo la matriz militarizada de las policías, el temor a la politización y la consideración de la seguridad como un servicio público esencial (Rodríguez-Alzueta, 2014). La negación del derecho colectivo a la sindicalización, además, fue avalada por la Corte Suprema en un reciente fallo judicial ${ }^{15}$. Se trata de una situación que se repite casi sin excepciones en toda América Latina. Uruguay es el único país en la región donde la Policía ha obtenido el derecho a sindicalizarse, aunque tiene vedada la posibilidad de realizar huelga (Calandrón; Galar; Lorenz, 2020). En Brasil, aunque restringidos en lo concerniente al derecho a huelga, los(as) agentes de la Policía Civil disponen de derechos sindicales en tanto es reconocida su condición de trabajadores estatales. Los miembros de la Policía Militar, en cambio, tienen prohibido sindicalizarse y participar en protestas, cuestión que no ha impedido la conformación de organizaciones y la convocatoria a movimientos huelguísticos, como han documentado Rabelo de Almeida (2011) y Cardoso Alves (2013). Carabineros de Chile constituye una fuerza militarizada que, con base en este argumento, tiene prohibida la sindicalización.

Una anécdota que consideramos ilustra muy bien esta dificultad que tienen los funcionarios de las fuerzas de seguridad de concebirse como trabajadores es la que nos narraba uno de los funcionarios traspasados a quien entrevistamos. Cuenta

14. Según el Artículo 535 del Decreto 1866/1983, se considera falta grave la interposición de recurso o reclamo colectivo.

15. El fallo validó la Ley 13982 que dispone que los(as) agentes de la Policía de la provincia de Buenos Aires no pueden "desarrollar actividades lucrativas o de cualquier otro tipo incompatibles con el desempeño de las funciones policiales”. Además, mencionó la introducción realizada, en 2013, a la Ley Orgánica de la Policía Federal Argentina (21965), que prohíbe cualquier actividad gremial de sus miembros (Centro de Información Judicial, 2017). Para un análisis de la audiencia pública previa a este fallo, ver Rodríguez Games (2016). 
que, al incorporar una aseguradora de riesgos de trabajo en todas las comisarías, la empresa dejó unos carteles que explicaban cómo proceder en caso de accidente, y cuyo encabezado era "Señor trabajador". Unos días después de haber pegado el cartel en un lugar visible de la dependencia, apareció con esa leyenda recortada.

Entonces, producto de esta forma de concebir su quehacer profesional, su apego a las normas y a la cadena de mando, los policías, en general, no se entienden como sujetos de derecho ni se han manifestado públicamente. En este sentido, un evento sin precedentes tuvo lugar durante el mes de octubre del año 2012, cuando se desató una protesta conjunta de dos fuerzas federales: la Prefectura Naval Argentina (PNA) y la Gendarmería Nacional Argentina GNA. El conflicto comenzó el martes 3 de octubre, el día después de la liquidación salarial del mes de septiembre. De acuerdo con la prensa gráfica, la mecha que encendió el reclamo fue el Decreto Presidencial 1307/2012, elaborado por el Ministerio de Seguridad de la Nación, que provocó una significativa reducción del salario, en nombre de la regularización salarial del personal de estas fuerzas de seguridad. La complejidad del régimen salarial del personal de las fuerzas de seguridad hizo que inicialmente se adjudicase la reacción a una liquidación incorrecta, más que al decreto señalado ${ }^{16}$ (Frederic, 2015). Casi un año después, en diciembre de 2013, se sucedieron una serie de protestas por parte de efectivos de policías provinciales en reclamo de mejoras salariales y de condiciones de trabajo, que afectaron a 21 provincias del país (Galar, 2017). Cabe mencionar que los miembros de la PFA no participaron como tales de ninguna de estas manifestaciones públicas.

Las características de la protesta de algunos de los funcionarios de la PFA traspasados a la PC que exigían ser reincorporados en su fuerza de origen fueron variando con el correr del tiempo. En una de las primeras, que como decíamos tuvo lugar en octubre de 2016, encontramos presencia de policías retirados y familiares de los(as) uniformados(as) a través de agrupaciones que los nucleaban, en particular de la Agrupación Azules por Siempre (grupo de policías retirados que incluye a gendarmes, prefectos y penitenciarios), y la Asociación Civil Viudas y Familiares de Policías Federales Caídos en Cumplimiento del Deber (ACVyF). La presencia de estos actores en los reclamos públicos policiales ha sido común, con la intención de evitarles sanciones disciplinarias por parte de la institución (Galar, 2018). Los funcionarios han encontrado, además, otros recursos para expresar sus reclamos y evitar que los

16. El régimen salarial de este sector del Estado argentino llevaba unos 20 años de distorsiones acumuladas producidas por la incorporación de suplementos salariales denominados en negro o no remunerativos. Esta situación inauguró, hace menos de una década, una catarata de reclamos judiciales por parte de los efectivos de las fuerzas de seguridad y armadas, aceptados y convertidos en medidas cautelares por algunos jueces federales. Como consecuencia, la liquidación salarial dejó de ser una atribución del poder ejecutivo y pasó a serlo de la justicia que, al dar lugar a las demandas, fue definiendo con criterios dispares la liquidación salarial correspondiente a cada afectado. 
mismos les generen problemas. En primer lugar, muchos han interpuesto recursos administrativos y tratado de agotar esa vía primero.

Otra forma de mostrar el descontento ocurrió hacia fines de 2018, cuando, a través de la comunicación por redes sociales y aplicaciones de mensajería, coordinaron para apagar al mismo tiempo todos los teléfonos celulares que permitían que la superioridad supiera dónde se encontraban y pudiera controlar que estuvieran cumpliendo el servicio. Fue así como lograron que se diera marcha atrás la tercera modificación en los horarios de servicio que se pretendía realizar en un lapso breve. Cabe mencionar que el teléfono con GPS $^{17}$ es una de las cuestiones que más molestan a los policías de su nuevo trabajo, pues lo consideran una forma de hostigamiento que no mejora el servicio que brindan. Además, estos dispositivos tienen dos problemas que para ellos son fundamentales: pierden la señal en los lugares donde más se necesitaría estar en contacto para pedir refuerzos, y permiten, a través de los mapas satelitales, que cualquiera sepa con exactitud dónde están posicionados, pudiendo cometer cualquier delito evadiendo la vigilancia policial. Apagar el teléfono de manera coordinada fue una acción de confrontación con la autoridad que no trascendió el espacio policial, pero que fue leída como victoriosa por parte de los policías, porque logro el cometido de evitar que se implementaran las reformas en sus horarios.

En las manifestaciones que se sucedieron frente a diferentes edificios públicos, tal vez las acciones más llamativas y novedosas, para la fuerza, fueron los propios policías, quienes le pusieron el cuerpo al reclamo. Estas tuvieron algunas particularidades, por ejemplo, para darle legitimidad, los funcionarios, en general, se manifestaron solo si estaban fuera de servicio o si no estaban cumpliendo funciones por alguna sanción. Se organizaron por turnos para ir acercándose a la manifestación a medida que terminaban su servicio. Es decir, nadie faltaba a su trabajo para ir a concentrar con sus compañeros; se repetía en la marcha la lógica laboral de los cuartos. De hecho, algo que muchos de los funcionarios dijeron en sus apariciones públicas en los medios, en el marco de un reclamo ante el ministerio de seguridad de la CABA, fue que, para no alterar la provisión del servicio de seguridad, se estaban relevando entre ellos para reclamar, y por eso el número de manifestantes era variable.

En ese sentido, buscaban diferenciarse de aquellos que habitualmente realizaban reclamos en la vía pública, y a quienes debían controlar como parte de su tarea policial. Una forma que encontraron para hacerlo fue manifestarse uniformados y armados, para no perder su identificación con la institución y su tarea. Con todo lo que esto significaba, por momentos nos encontrábamos con más de 500 policías armados parapetados frente a distintos edificios públicos en situación de rebeldía. 
Tampoco cortaron calles ni impidieron la libre circulación de vehículos o transeúntes. Buscaban distanciarse de aquellos a quienes asociaban con la alteración del orden y la conflictividad en la vía pública, los piqueteros, y rechazaban la clasificación de su acción colectiva como manifestación. De esta manera, son ilustrativos los dichos del cabo primero Ricardo Braustein, uno de los que encabezó el reclamo, en el programa La Mañana, de AM750: "Me duele estar haciendo esto, tener que usar estos métodos y que el personal de Ciudad nos diga que somos 'piqueteros'. Solamente estamos reclamando algo que ellos se comprometieron a cumplir". Vale aclarar que en ningún momento escuchamos empatía de los manifestantes policiales con alguna otra expresión de descontento: marchas, cortes de calles, toma de lugares de trabajo o cualquier otra manifestación.

Así, un elemento más que contribuyó a reforzar la identidad de estos manifestantes distanciándola de cualquier otra fue cómo se reproducían elementos del mundo de las fuerzas de seguridad y militares en la misma protesta. Por ejemplo, se formaban en orden como para cualquier acto o conmemoración institucional frente a los edificios públicos como parte de la manifestación. También se cantaba el himno argentino. Cuando alguno de los funcionarios que lideraban el reclamo se dirigía a los demás policías que se encontraban formados, lo hacía en voz fuerte, clara y firme, como dando una orden de mando, y cuando hablaban lo hacían arengando, como se estila en los actos castrenses. Los policías que se manifestaron dijeron no tener líderes y ser autoconvocados; sin embrago, es posible identificar algunas figuras que emergieron como voz cantante del reclamo y que coincidían con la jerarquía policial. Observamos manifestaciones que reproducían un acto institucional con las jerarquías incluidas.

Los manifestantes han denunciado que la PC persigue a quienes participan de las protestas, en la mayoría de los casos a través de sanciones que tienen implicancias materiales para los funcionarios, ya que se les descuentan los días e, incluso, algunos han sido cesanteados. Juan Mármol, uno de los funcionarios que encabezó el reclamo, al consultarle por qué ocupó ese lugar, explicaba que se debió a que revistaba en un destino con mucha visibilidad, el servicio de Plaza de Mayo, permitiéndole conocer a importantes figuras públicas, lo que le ayudó a escalar sus reivindicaciones. Además, destacaba su poder de persuasión sobre los demás. En una de las manifestaciones arengaba de esta forma a sus compañeros formados:

El policía federal prefiere morir de pie antes que inclinarse por vicios económicos. Somos policías federales y no estamos en contra de que la ciudad autónoma tenga su propia policía, pero no arbitrando estos medios los cuales nos privan y nos prohíben de desempeñar nuestra labor en todo el territorio federal. Hoy estamos acá para que nos 
atiendan y escuchen el reclamo, para algunos injusto para otros justo, todos los aquí presentes tenemos un ideal que es morir de pie con la farda azul y no de rodillas inclinándose a los vicios económicos. El personal de la PFA tiene templanza y sigue sus ideales.

Vemos cómo, en su arenga, este funcionario resalta la identificación con la institución de origen $y$, también, pone el énfasis en dejar claro que el motivo del reclamo no es de índole material, sino por el sentido de pertenencia que tienen con la PFA. Como explicábamos anteriormente, el reclamo aúna las pérdidas de algunas condiciones laborales (posibilidad de movilidad dentro del territorio del país, la obra social y el horario de trabajo) con las pérdidas simbólicas, pero cuando se explicita siempre es en clave de la identificación con la PFA y no en su condición de trabajadores.

El carácter pretendidamente apolítico de las prácticas e intenciones de los actores es una constante en el mundo policial y se hace presente fuertemente en las manifestaciones donde los participantes buscan remarcarlo. La política es entendida por los policías como una sustancia ajena, sucia e interesada en beneficios personales. Subyace a este tipo de valoraciones una narrativa más amplia que diferencia una práctica interesada, en términos económicos, sociales o políticos, de una práctica desinteresada, orientada exclusivamente a la búsqueda del bienestar del personal policial. Esta narrativa, por lo demás, conecta con el sentido sacrificial otorgado a la actividad policíaca, una profesión que se entiende en términos de servicio o misión (Galar, 2018).

En este sentido, los exmiembros de la PFA que se posicionan en contra de su traspaso a una nueva fuerza dicen no tener ninguna motivación política en su reclamo, simplemente consideran que se han visto modificadas sus condiciones de trabajo y que no han sido debidamente consultados antes de tomar una medida que los afecta. Llama la atención que, en una institución jerárquica y vertical, que se sostiene en el cumplimiento de órdenes, los funcionarios reclamen por tener que acatar esta disposición. Una posible respuesta está vinculada a que el traspaso es una decisión tomada desde las esferas de gobierno, es política, y no desde la institución. Los funcionarios policiales consideran más legitimas las órdenes provenientes de su propia superioridad que de los responsables políticos a cargo de la seguridad. En este sentido, se observa una dificultad, por parte de las autoridades del área de seguridad del gobierno de la CABA, de sostener una conducción sobre la fuerza: en sus dos años de existencia, la fuerza ya ha tenido tres jefes. El primero de ellos fue José Potocar, que renunció luego de ser condenado por hechos de corrupción cuando revistaba como comisario en la PFA; luego fue el turno de Carlos Kevorkian, quien estuvo a cargo de la institución entre diciembre de 2017 y agosto de 2018, cuando abandonó el puesto aduciendo motivos personales; y fue sucedido por quien le seguía en la cadena de mando, Gabriel Berard. 
Vemos que se trata de manifestaciones callejeras que mantienen la jerarquía de la institución y que recurren a los rituales de formación y arenga vinculados a los actos policiales. Destacamos también que los policías se diferencian explícitamente de otros manifestantes y que consideran que sus reclamos no son políticos.

\section{Construyendo redes: la canción}

Queremos dar cuenta en este apartado de una de las formas que tuvo la protesta: la circulación de videos por redes sociales, siendo Facebook la principal red de distribución, aunque se usaron otras también. Los policías difundieron distinto tipo de información (bajas en los salarios, falta de aportes, reuniones, manifestaciones y opiniones sobre la política de gobierno) a sus compañeros a través de estos medios.

Para nuestros entrevistados las redes eran una fuente de referencia: "¿Vieron el video que circula de Macri con un texto que dice: 'policías los apoyo en todo lo que hagan'?", "Si quieren saber más del traspaso, vean los videos que hicimos", y también nos pasaron una foto que dice "Aguante, Chocobar" ${ }_{18}$. A través de diferentes comentarios, en todas las charlas las redes forman parte de las relaciones entre policías. A veces son el único medio por el que circula información sobre lo que pasa dentro de la fuerza, ya que no se pueden organizar ni tampoco dar declaraciones a la prensa sin expresa autorización de la jefatura ${ }^{19}$.

A lo largo del trabajo, dimos cuenta de distintos videos que circularon mostrando descontento frente al traspaso. Nos gustaría detenernos ahora en uno en particular que se compartió bastante entre los policías y que condensa muchas de las cuestiones a las que hicimos referencia en este artículo. El video se trata de un policía con el uniforme de la PFA, tocando la guitarra y entonando una versión de Canción para mi muerte de Sui Generis ${ }^{20}$, técnicamente es simple pero está bien realizado, el sonido

18. Luis Chocobar era funcionario de la Policía Local del municipio de Avellaneda. Estando de franco de servicio, el policía le disparó por la espalda a Pablo Kukoc y lo asesinó, mientras se daba a la fuga, luego de haber herido a puñaladas a un turista estadounidense para robarle su cámara. A pesar de que la justicia consideró que el funcionario se excedió en la legítima defensa y se encaminaba a un juicio oral, fue recibido por el presidente Mauricio Macri y la ministra Bullrich, quienes respaldaron su accionar.

19. El Artículo 34 de la Reglamentación de la Ley para el Personal de la Policía Federal Argentina (Decreto 1866/83) lo deja claro: salvo autorización expresa de la Jefatura, el personal en actividad o retiro no podrá prestarse a reportajes ni emitir públicamente su opinión en asuntos de carácter oficial o vinculados a la función o a los intereses policiales. Esa autorización deberá canalizarse en todos los casos por intermedio del Departamento de Comunicación Social.

20. Grupo musical la década del setenta, integrado por Charly García y Nito Mestre. 
es impecable. Al policía no se le ve la cara, solo la gorra y el texto de la canción va expandiéndose a modo de subtítulo. El texto es el siguiente (la música es la original):

Hubo un tiempo que fue hermoso y fui poli de verdad

Caminaba por las calles y tenía autoridad

Poco a poco fui perdiendo mis derechos y mi amor

Me pusieron GPS

Me vistieron de Bordó

Te encontraré una mañana en el sol de capital

Y será mi escudo el emblema nacional

Miau miau miau por qué te voté

Nuestros jefes nos vendieron, siempre fue la corrupción

El lavado de dinero vale más que un batallón

Ya no usan más bigote, no se plantan frente a un juez,

Achupinan pantalones, NO TE QUIEREN DEFENDER

Y con esto me retiro no tengo jurisdicción,

Me controlan los vecinos y la última promoción

Ya no tengo jerarquía, ya no tengo vocación.

Ya no soy más policía,

Soy empleado del Guasón. (Noticias en Red, 2018)

Los reclamos y el descontento de una porción de los policías de la PFA traspasados a la PC que venimos analizando se encuentran sintetizados en la letra que escribió o escribieron estos policías. Los uniformados consideran que los policías locales no son de verdad, no quieren ser pitufos, quieren tener autoridad. El policía de la canción y sus compañeros han perdido derechos laborales, aportes, adicionales e incluso su amor y vocación por la profesión.

Encontramos en la canción referencias a un modelo de policiamiento que los policías entrevistados consideran pura ficción, pero que es el que el gobierno de la CABA intentó instalar: una policía joven, de cercanía y con mucha tecnología a disposición. Ese modelo que buscan imponerle a los policías se resume en una vestimenta que rechazan, un pantalón achupinado (símbolo de la juventud, modernidad y que no consideran masculino). También se hace mención en la canción a la tecnología de rastreo satelital que mencionábamos anteriormente ("me pusieron GPS"), resaltando el control sobre los funcionarios que implica tener un teléfono que todo el tiempo informa sobre sus movimientos a los superiores. Un seguimiento permanente que es presentado por las autoridades del Ministerio de Justicia y Seguridad de la Ciudad de Buenos Aires como un rasgo novedoso y positivo de la PC que incorpora tecnología. A su vez, estos policías se sienten controlados por los 
vecinos, e incluso por colegas más jóvenes y de menor trayectoria, producto de las modificaciones en la escala jerárquica.

Hay también un reclamo a los cuadros superiores de la PFA que permitieron que esta transferencia de funciones fuese posible e, incluso, se entrevé que existen intereses espurios detrás de la misma. El cierre es interesante: los traspasados pierden su condición de policías, se le quita todo el valor simbólico a la función y se convierten en "empleados del Guasón" (Larreta).

\section{Conclusiones}

Para concluir, podemos decir que no todos los policías traspasados de la PFA a la PC se manifestaron y que aquellos que eligieron mostrar su disconformidad no lo hicieron de la misma manera. Algunos quieren volver a la PFA y muchos aceptan el nuevo destino, pero les gustaría no perder derechos laborales.

La disconformidad de algunos de los funcionarios de la PFA traspasados, que no solo tiene que ver con los derechos y condiciones laborales que se pierden o modifican con esta transformación institucional, sino también con un sentido de pertenencia muy arraigado a la fuerza de origen, se impone a las restricciones legales y morales para reclamar. Disconformidad que se pone en acto en los distintos reclamos organizados en el espacio público, pero también en el material que circula por redes sociales.

Se presenta entonces una tensión entre si se trata de un reclamo por las condiciones de trabajo y el salario o por una cuestión identitaria. Si tiene que ver con un sentido de pertenencia a la institución, demostraría que la misma, a través de sus publicaciones y discursos, ha logrado que los funcionarios entiendan su quehacer profesional como una vocación y no como un trabajo. Si se trata de una cuestión identitaria, este conflicto se resuelve reincorporando a los policías traspasados a la PFA. Si es por condiciones laborales y salariales, una vez resueltas las mismas los funcionarios no deberían tener problema en permanecer en la PC. Existe tensión entre una motivación que se puede considerar más mundana o material, la que tiene que ver con el salario y las condiciones laborales, y otra que podemos denominar simbólica, que tiene que ver con la historia, valores y rituales que se asocian a la fuerza de origen. Esta última sería más legítima que la primera. Algo interesante de analizar es si los funcionarios sienten vocación de servicio en general, independientemente de la institución a la que pertenezcan, o si su sentido de pertenencia es para con una fuerza en particular. Es decir, si su sentido de vocación es para con la función policial o para con una institución. 
Por otro lado, es importante señalar que, si bien el reclamo por parte de los funcionarios traspasados implica una ruptura de la cadena de mando, un acto de desobediencia a las normativas que los rigen, no implica un cuestionamiento más amplio a la institución ni un pedido de democratización o posibilidad de sindicalización. Es interesante también marcar que mientras que la manifestación implica una acción que está por fuera de la estructura vertical y jerárquica de la institución, al mismo tiempo, se genera una obediencia a los líderes que encabezan el conflicto. Además, cabe destacar que el hecho de que los policías se manifiesten públicamente no parece haber contribuido a producir una identificación o acercamiento con otros actores que también protestan en la escena pública. El hecho de que los funcionarios de las fuerzas de seguridad, aun a la hora de manifestarse, conserven aquello que los identifica como tales (arma y uniforme) y recurran a elementos del mundo castrense (formarse y cantar el himno) así lo demuestra.

\section{Referencias}

Anitua, Gabriel Ignacio (2004). ¿Puede la institución policial ser actor de políticas de seguridad ciudadana? En La relación seguridad-inseguridad en centros urbanos de Europa y América Latina. Estrategias, políticas, actores, perspectivas y resultados (pp. 169-192), editado por Ignacio Muñagorri; Juan Pegoraro. Madrid: Dykinson.

Bover, Tomás; Maglia Elea (2017). ¿Están preparados para morir? La muerte en la profesión policial. Avá, 30, 159-180.

Calandrón, Sabrina (2014). Género y sexualidad en la Policía bonaerense. San Martín: UNSAM.

Calandrón, Sabrina; Galar, Santiago; Lorenz, Mariana (2020). El proceso de sindicalización de los gremios policiales en Uruguay. Iconos [en imprenta].

Cardoso-Alves, Juliana do Carmo (2013). Narrativas de praças acerca do movimento reivindicatório da Polícia militar de Minas Gerais. Tempos Históricos, 17, 183-212.

Centro de Información Judicial (11 de abril de 2017). La Corte Suprema por mayoría resolvió que la Policía de la Provincia de Buenos Aires no tiene derecho a sindicalizarse. Recuperado de https://www.cij.gov.ar/nota-25566-La-Corte-Suprema-por-mayor-a-resolvi--que-la-Polica-de-la-Provincia-de-Buenos-Aires-no-tiene-derecho-a-sindicalizarse.html

Conclusión TV (1 de octubre de 2016). Protesta de la Policía Federal por traspaso a la ciudad de Buenos Aires [video]. Recuperado de https://www.youtube.com/watch?v=Uf6UV-mlxUA 
Frederic, Sabina (2009). En torno a la vocación policial y el uso de la fuerza pública: identidad y profesionalización en la policía de la provincia de Buenos Aires. En La policía en perspectiva histórica. Argentina y Brasil, organizado por Ernesto Bohoslavsky; Lila Caimari; Cristiana Schettini. CD-Rom.

Frederic, Sabina (2015). ¿Militares, asalariados o trabajadores? El valor de lo justo y del bienestar en las evaluaciones morales sobre un "conflicto" gremial de la Gendarmería Nacional Argentina. Dilemas UFRJ. CD-Rom.

Galar, Santiago (2017). Policías en acción. Hacia una caracterización de la red de activistas vinculados a la institución policial en la región metropolitana. Argumentos, 19, 43-63.

Galar, Santiago (2018). Cuestionar el orden. Un análisis de los reclamos públicos de la familia policial en la provincia de Buenos Aires y la Ciudad de Buenos Aires. Trabajo y Sociedad, 31, 125-139.

Galvani, Mariana (2009). Fuerzas de Seguridad en la Argentina: un análisis sociológico y comunicacional de la construcción de identidad de/en la Policía Federal Argentina [Tesis de doctorado]. Universidad de Buenos Aires, Buenos Aires, Argentina.

Galvani, Mariana (2016). Cómo se construye un policía. La Federal desde adentro. Buenos Aires: Siglo XXI.

Garriga-Zucal, José (2014). "Por el pancho y la coca". Apuntes sobre las representaciones del trabajo entre los policías de la provincia de Buenos Aires. Papeles de Trabajo, 8(13), 34-53.

Garriga-Zucal, José (2016). El verdadero policía y el correctivo. Esbozos para una interpretación de la violencia policial. De Prácticas y Discursos, 5(6), 1-23.

Lorenz, Mariana (2017a). El “verdadero" trabajo policial. Representaciones de los funcionarios de la Policía Federal Argentina acerca de su quehacer profesional. Papeles de Trabajo, 11(19), 99-120.

Lorenz, Mariana (2017b). Definiendo la profesión policial. Trabajo y Sociedad, 30, 99-118.

Melotto, Mariano (2013). Aprender a desear lo posible: la construcción de la vocación y el espiritu de cuerpo en escuelas de formación básica policial. En De armas llevar. Estudios socio antropológicos de los quehaceres de policías y de las fuerzas de seguridad (pp. 241-270), editado por Sabina Frederic; Mariana Galvani; José Garriga; Brigida Renoldi. La Plata: Universidad de la Plata.

Monjardet, Dominique (2010). Lo que hace la policía. Sociología de la fuerza pública. Buenos Aires: Prometeo.

Noticias en Red (19 de junio de 2018). La particular protesta de un policía contra el traspaso de la Federal a la Policía de la Ciudad [video]. Recuperado de https://www.youtube.com/ watch?v=fZU2X-A5HuA 
Policía Federal Argentina (200o). Letras en azul: poesías de nuestra gente. Buenos Aires: Editorial Policial.

Policía Federal Argentina (2006). Letras en azul II: poesías de nuestra gente. Buenos Aires: Editorial Policial.

Policías en acción (de protesta) (28 de marzo de 2018). Página 12. Recuperado de https://www. pagina12.com.ar/104466-policias-en-accion-de-protesta

Policías y familiares rechazan el traspaso de la policía Federal a la ciudad ( 3 de enero de 2017). Télam [video]. Recuperado de https://www.youtube.com/watch?reload=9\&v=GhkCyvQhy5c

Rabelo de Almeida, Juniele (2011). Tropas em greve: militarismo e democratização no ciclo de protestos dos policiais militares brasileiros. Sæculum, 24, 105-122.

Rebelión en la Policía de la Ciudad: efectivos le recriminaron a Ocampo la falta de recursos (26 de abril de 2017). Nueva Ciudad. Recuperado de https://www.nueva-ciudad.com.ar/ notas/201704/32262-rebelion-en-la-policia-de-la-ciudad-efectivos-le-recriminaron-aocampo-la-falta-de-recursos.html

Ríos, Alina. Lis (2010). Gubernamentalidad y poder de policía: la articulación de un modelo de policiamiento dual en Buenos Aires, 2004-2007. CADERNO CRH, 23(60), 487-510.

Ríos, Alina Lis (2016). El traspaso de la Federal: policía y orden social. En Macri lo hizo (pp. 139-150), editado por Ari Lijalad. Buenos Aires: Continente y Peña Lilo.

Rodríguez, Adolfo (1978). Historia de la Policía Federal Argentina. Buenos Aires: Editorial Policial.

Rodríguez, Adolfo; Zappietro, Eugenio (1999). Historia de la Policía Federal Argentina a las puertas del tercer milenio. Génesis y desarrollo desde 1950 hasta la actualidad. Buenos Aires: Editorial Policial.

Rodríguez-Alzueta, Esteban (2014). Acuartelamiento y saqueo: protesta policial y social. Pensamiento Penal, 1-22. Recuperado de http://www.pensamientopenal.com.ar/doctrina/38121-acuartelamiento-y-saqueo-protesta-policial-y-social

Rodríguez-Games, Nicolás (2016). Estudio introductorio. En ¿El gremio de la gorra? Trabajo y sindicalización policial: ejes para una discusión (pp. 15-57), coordinado por Marcelo Saín; Nicolás Rodríguez-Games. Buenos Aires: Octubre.

Sirimarco, Mariana (2009). De civil a policía. Una etnografía del proceso de incorporación a la institución policial. Buenos Aires: Teseo.

Suárez de Garay, María Eugenia (2006). Los policias: una averiguación antropológica. Guadalajara: ITESO. 
Valles, Miguel (200o). Técnicas cualitativas de investigación social. Reflexión metodológica y práctica profesional. Madrid: Síntesis.

Vasilachis de Gialdino, Irene (1992). Métodos cualitativos I. Los problemasteórico-epistemológicos. Buenos Aires: CEAL.

Zappietro, Eugenio (2005). Cien preguntas básicas sobre el origen y la evolución de la Policía Federal Argentina. Buenos Aires: Editorial Policial.

Zappietro, Eugenio (2010). Historia de la Policía Federal Argentina en el bicentenario del 25 de mayo de 181o. Buenos Aires: Editorial Policial. 